zen kann eine Bestätigung der abgeleiteten Formeln von der Erfahrung erwartet werden. Sollten jedoch sehr erhebliche Abweichungen vorkommen, so mülste das $\mathbf{M a -}$ riotte'sche Gesetz durch jenes schon erwähnte strengere ersetzt werden, welches eigentlich die Relation zwischen Druck und Dichte in diesem Falle angiebt. $\mathrm{Ob}$ nicht Umstände anderer Art störend einwirken, oder ob die Arbeitsmessung mit derart hinlänglicher Sicherheit vollzogen werden kann, dafs eine Bestimmung des Verhältnisses der Wärmecapacitäten möglich wird, wage ich nicht zu entscheiden.

Brünn, 1. Februar 1876.

\title{
XV. Ueber die physikalischen Eigenschaften des
} Galliums; von Hrn. Lecoq de Boisbaudran. (Journ. de physique, T. V, p. 277.)

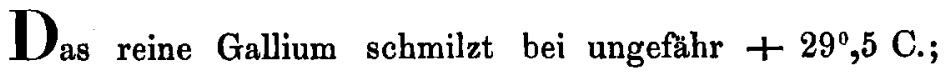
es schmilzt also rasch, so wie man es in die Hand legt. Wenn es vollständig geschmolzen ist, hält es sich aufserordentlich leicht in Ueberschmelzung. Im Februar und März hielt sich ein Kügelchen in der Luft meines Laboratoriums zu Cognac länger als einen Monat flüssig, obwohl es jeden Tag mit einem Stahlstift zertheilt und wieder vereinigt ward und $z$ war bei Temperaturen, die mehrmals zu Null und vielleicht selbst darunter herabgingen. Das überschmelzte Gallium gesteht so wie man es mit einem Stückchen festen Galliums berührt.

Unter $+29^{\circ}, 5$ oder in der Kälte und in Ueberschmelzung ist das füssige Gallium sehr beweglich, aber scheinbar mit einem dünnen Häutchen überzogen, unter welchem man das Metall fliefsen sieht, wenn man die Röhre, welche es enthält, neigt. Es haftet am Glase, anf welchem es sich beim Reiben mit einem Stäbchen leicht ausbreitet.

Selbst wenige Grade unter seinem Schmelzpunkt ist 
das starre Gallium hart und für ein so leicht schmelzbares Metall merkwürdig zähe, defsungeachtet läfst es sich mit einem Messer leicht schneiden, wie ein schmiedbares Metall und zeigt in dieser Beziehung einige Analogie mit dem Aluminium.

Das Gallium krystallisirt mit grofser Leichtigkeit. Eine kleine fast sphärische Masse von 6 Centigramm, der lösenden Wirkung der Chlorwasserstoffsäure ausgesetzt, erlangte recht nette polyedrische Umrisse und so ausgedehnte Flächen, wie wenn die ganze Masse einem einzigen Krystall angehört hätte.

An der Luft bis zur lebhaften Rothgluth erhitzt, oxydirt sich das Gallium nur sehr schwach an der Oberfläche und verflüchtigt sich nicht.

Eins der hervorstechendsten Kennzeichen des Galliums ist die Bildung eines Spectrums, gebildet aus zwei violetten Linien, deren hellste 417,0 zur Wellenlänge hat, die andere 403,1. Diefs Spectrum erhält man, wenn man den Inductionsfunken auf eine Salzlösung von Gallium überspringen läfst; es ist ein sehr empfindliches Reagens auf das neue Metall. In der Gasflamme beobachtet man dagegen nur mit grolser Mühe eine schwache Spur der Linie 417.

Die Dichtigkeit des Galliums (vorläufig bestimmt an einem $6,{ }^{\text {cg }} 4$ wiegenden Stücke) fand sich $=4,7$, wonach es zwischen dem Aluminium und Indium stehen würde.

\section{Berichtigung; von F. zöllner.}

In meinem Aufsatze zur Geschichte des W eber'schen Gesetzes" (diese Annalen, Bd. 158, S. 472, Juli-Heft 1876) habe ich S. 479 "perpetual motion" durch "beharrliche Bewegung " übersetzt. Wie ich nachträglich belehrt worden bin, besitzt die englische Sprache kein besonderes Wort, um den Begriff einer „beharrlichen Bewegung“ von dem 